\title{
Mitochondrial dynamics, quality control and miRNA regulation in skeletal muscle: implications for obesity and related metabolic disease
}

Citation for published version (APA):

Dahlmans, D., Houzelle, A., Schrauwen, P., \& Hoeks, J. (2016). Mitochondrial dynamics, quality control and miRNA regulation in skeletal muscle: implications for obesity and related metabolic disease. Clinical Science, 130(11), 843-852. https://doi.org/10.1042/CS20150780

Document status and date:

Published: 01/06/2016

DOI:

10.1042/CS20150780

Document Version:

Publisher's PDF, also known as Version of record

Document license:

Taverne

Please check the document version of this publication:

- A submitted manuscript is the version of the article upon submission and before peer-review. There can be important differences between the submitted version and the official published version of record.

People interested in the research are advised to contact the author for the final version of the publication, or visit the DOI to the publisher's website.

- The final author version and the galley proof are versions of the publication after peer review.

- The final published version features the final layout of the paper including the volume, issue and page numbers.

Link to publication

\footnotetext{
General rights rights.

- You may freely distribute the URL identifying the publication in the public portal. please follow below link for the End User Agreement:

www.umlib.nl/taverne-license

Take down policy

If you believe that this document breaches copyright please contact us at:

repository@maastrichtuniversity.nl

providing details and we will investigate your claim.
}

Copyright and moral rights for the publications made accessible in the public portal are retained by the authors and/or other copyright owners and it is a condition of accessing publications that users recognise and abide by the legal requirements associated with these

- Users may download and print one copy of any publication from the public portal for the purpose of private study or research.

- You may not further distribute the material or use it for any profit-making activity or commercial gain

If the publication is distributed under the terms of Article $25 \mathrm{fa}$ of the Dutch Copyright Act, indicated by the "Taverne" license above, 


\title{
Mitochondrial dynamics, quality control and miRNA regulation in skeletal muscle: implications for obesity and related metabolic disease
}

\author{
Dennis Dahlmans*1, Alexandre Houzelle*1, Patrick Schrauwen* and Joris Hoeks* \\ *Department of Human Biology and Human Movement Sciences, NUTRIM School of Nutrition and Translational Research in Metabolism, Maastricht \\ University, PO Box 616, 6200 MD Maastricht, the Netherlands
}

\begin{abstract}
The western dietary habits and sedentary lifestyle largely contributes to the growing epidemic of obesity. Mitochondria are at the front line of cellular energy homoeostasis and are implicated in the pathophysiology of obesity and obesity-related metabolic disease. In recent years, novel aspects in the regulation of mitochondrial metabolism, such as mitochondrial dynamics, mitochondrial protein quality control and post-transcriptional regulation of genes coding for mitochondrial proteins, have emerged. In this review, we discuss the recent findings concerning the dysregulation of these processes in skeletal muscle in obesogenic conditions.
\end{abstract}

Key words: metabolic disease, microRNAs, mitochondria, obesity, skeletal muscle.

\section{INTRODUCTION}

Over the last 30 years, the prevalence of overweight and obesity combined has increased by $27.5 \%$ for adults and by $47.1 \%$ for children [1]. Excessive caloric intake, often in combination with a sedentary lifestyle, underlies the augmentation in fat deposition, which not only occurs in adipose tissue but also in non-adipose, ectopic sites such as skeletal muscle. In turn, the accumulation of lipids in skeletal muscle is tightly correlated to insulin resistance of that tissue, an important hallmark in the development towards type 2 diabetes mellitus (T2DM) [2]. Since skeletal muscle accounts for the majority of post-prandial glucose uptake, this tissue is considered as a major player in obesity-related metabolic disturbances [3].

Clearly, the main determinant of ectopic fat storage is the balance between the supply and the oxidation of fatty acids. With respect to the latter, an extensive amount of research reports were published over the last decade showing that skeletal muscle from obese (insulin-resistant) subjects is characterized by smaller mitochondria, reduced mitochondrial content, (fat) oxidative capacity and respiratory chain activity as well as increased production of reactive oxygen species and intramyocellular triacylglycerol content [4-7].
In recent years however, new insights highlighted the importance of additional aspects of mitochondrial function, also in relation to obesity and obesity-related metabolic disturbances. Thus, it has become increasingly clear that mitochondria are not single organelles, but combine into tightly regulated, dynamic networks that are constantly built, renewed and subjected to quality control mechanisms [8]. To maintain proper mitochondrial morphology and overall function, dysfunctional parts of mitochondria can be split off (fission), and degraded via a process called mitophagy. Furthermore, new functional mitochondria can fuse with other mitochondria (fusion), in order to adapt to changes in energy demand. Furthermore, the mitochondrial proteome is subject to quality control mechanisms, primarily performed by chaperone proteins, that assist in the folding of misfolded or unfolded proteins, as well as by proteases that degrade misfolded proteins [9]. Finally, miRNAs, small non-coding RNA strands that regulate the stability and translation of conventional messenger RNAs by base pairing with protein-coding transcripts, add a new level of regulation and fine-tuning for gene expression and protein output, also with respect to mitochondrial metabolism.

This review will focus on these 'novel' aspects influencing skeletal muscle mitochondrial metabolism and will discuss the recent findings in relation to obesity and related metabolic

Abbreviations: CIpXP, ATP-dependent caseinolytic mitochondrial matrix protease complex; Drp-1, dynamin-related protein 1; ETC, electron transport chain; Fis1, fission protein 1; FOXJ3, Forkhead Box J3; IMS, mitochondrial intermembrane space; LC3, microtubule-associated protein 1A/1B-light chain 3 proteins; IncRNA, long non-coding RNA; LonP, Lon protease; mff, mitochondrial fission factor; Mfn-1, mitofusin-1; Mfn-2, mitofusin-2; MID49/51, mitochondrial dynamics proteins of 49 and 51 kDa; Mrps-5, mitochondrial ribosomal protein subunit 5 ; mtDNA, mitochondrial DNA; MTS, N-terminal matrix-sequence; mtTFA, mitochondrial transcription factor A; mtUPR, mitochondrial unfolded protein response; Opa1, optic atrophy 1; PARP-2, poly(ADP-ribosyl) transferase-like 2 protein; PBMC, peripheral blood mononuclear cell; PINK1, PTEN-induced putative kinase 1; RISC, RNA induced silencing complex; ROS, reactive oxygen species; T2DM, type 2 diabetes mellitus; UPR, unfolded protein response.

1 These authors contributed equally to this work. 
disease. Thus, we will discuss the processes of mitochondrial dynamics and protein quality control in skeletal muscle and review the relevant literature on their dysregulation in obesity and obesity-related metabolic disturbances. Additionally, we will discuss miRNAs that have emerged as potential regulators of mitochondrial dynamics, metabolism and biogenesis.

\section{MITOCHONDRIAL DYNAMICS}

Rather than being single organelles, mitochondria are organized in a dynamic network to maintain proper physiological function in cells. Perpetual cycles of fission and fusion associated with mitochondrial remodelling is the core of mitochondrial dynamics. These tightly regulated processes involve specific protein machineries to adapt to changes in the cellular environment. Mitochondrial fusion allows the integration of the organelle's contents and the maintenance and restoration of its membrane potential. On the other hand, mitochondrial fission is activated to provide the cells with the appropriate amount of mitochondria and is the first step to prime damaged mitochondria for removal through mitophagy [10]. In physiological conditions, mitochondrial fission and fusion are balanced and provide the cells with a safeguard to keep a healthy and functional mitochondrial population [10].

Mitochondrial dynamics is a well-conserved mechanism, governed by GTPases that facilitate the mitochondrial remodelling associated with the fusion/fission processes. The mitofusins (Mfn-1, Mfn-2) are embedded in the outer membrane via their transmembrane domains and regulate the fusion of the mitochondrial outer membranes. Once outer membranes fuse, optic atrophy 1 (Opa1) proteins, mostly present at the inner membrane, participate in the mitochondrial morphological remodelling and the fusion of the inner membranes [11]. Altogether this mechanism ensures the communication between mitochondria, the (re)distribution of the mitochondrial DNA (mtDNA) pool and is part of the damage removal process. Mitochondrial fission is mainly mediated via the dynamin-related protein 1 (Drp-1) and its outer membrane receptors, fission protein 1 (Fis1), mitochondrial fission factor (Mff) and mitochondrial dynamics proteins of 49 and $51 \mathrm{kDa}$ (Mid49/51). Drp-1 can be recruited by one of the four receptors. Although the mechanisms are incompletely understood, it has been shown that Mid49/51 can promote Drp-1 mediated fission without the presence of Mff and Fis1. Furthermore, Mff and Fis1, more than being mere receptors also enhance Drp-1 phosphorylation and oligomerization hence promoting and strengthening mitochondrial fission [12]. Following fission, healthy mitochondria will enter a short solitary period before being reintegrated into the mitochondrial network via the fusion mechanism. Unhealthy mitochondria depolarize and are disposed of by mitophagy [13]. The continuous cycle of mitochondrial fusion and fission, including mitophagy, is depicted in Figure 1.

\section{Mitochondrial dynamics in lipid overload}

A good balance between fusion and fission is crucial for the maintenance of a proper mitochondrial function, also in skeletal muscle. It is therefore not surprising that the link between meta- bolic disorders, associated with mitochondrial dysfunction, and mitochondrial dynamics has been addressed in a number of studies.

Incubating cultured $\mathrm{C} 2 \mathrm{C} 12$ myotubes with palmitate, a commonly used in vitro approach to mimic the lipid overload that characterizes obesity, increased the levels of the fission proteins Drp1 and Fis 1 by $\sim 50 \%$, which was accompanied by an increased number of small, fragmented mitochondria as observed by electron microscopy. Furthermore, the fragmented mitochondria also generated more reactive oxygen species (ROS) while producing less ATP. Interestingly, C2C12 myotubes, treated with palmitate and Mdivi-1, a Drp-1 inhibitor, displayed reduced mitochondrial fission and partially recovered their basal ROS production, membrane potential and glucose uptake in vitro and in vivo [14]. With respect to the fusion process, palmitate-incubated $\mathrm{C} 2 \mathrm{C} 12$ myotubes did not display a change in mitofusin and Opa1 protein expression levels [14]. However, when incubated with a higher concentration of palmitate for a more prolonged period, L6 rat skeletal muscle cells showed a $48 \%$ reduction in Mfn- 2 protein levels associated with a $32 \%$ reduction in insulin-stimulated glucose uptake [15]. Similar to previous observations, palmitate incubation of these L6 cells led to lower mitochondrial membrane potential and higher ROS production [15]. Together, these studies suggest that high palmitate levels can lead to mitochondrial fragmentation via activation and inhibition of fission and fusion, respectively.

Furthermore, in vivo animal studies revealed that 40 weeks of high-fat feeding decreased both protein levels of Mfn-1 and Mfn- 2 in skeletal muscle by $20 \%$, which was associated with a $50 \%$ increase in Fis 1 and Drp-1 protein levels [16]. These high-fat diet-induced changes were paralleled by a $25 \%$ reduction in ADP-stimulated oxygen consumption rate, a lower respiratory control ratio, a reduced ATP production and a reduced mitochondrial content exchange (i.e. the dynamic propagation of a GFP-tagged mitochondrial protein through the mitochondrial network), as observed using confocal microscopy to study mitochondrial dynamics in living animals [16]. Although focused on the liver, another study compared high-fat diets with different fat composition (lard compared with fish-oil) and found that rats fed a high-lard diet, showed an increased number of small and fragmented liver mitochondria as well as reduced Mfn-1, Mfn2 and Opa1 and increased Drp-1 and Fis 1 levels, as compared with both the high fish-oil and chow diet [17]. Furthermore, oxygen consumption rates were reduced whereas ROS production was augmented in the high-lard diet group compared with both the high fish-oil and chow diets [17]. Similar observations were made in skeletal muscle from both leptin-deficient $(o b / o b)$ mice fed on normal-diet and wild-type mice fed on high-fat diet [14]. In both conditions, electron microscopy revealed the presence of small fragmented mitochondria in muscle biopsies. At the protein level, Drp-1 and Fis1 levels were increased in both genetically and diet-induced obese mice. However, fusion proteins were not affected in these obese animals compared with controls. Furthermore, in vivo inhibition of mitochondrial fission using Mdivi-1, restored insulin-resistance indexes (i.e. the product of the areas under the glucose and insulin curves) during an oral glucose tolerance test in $o b / o b$ mice [14]. 


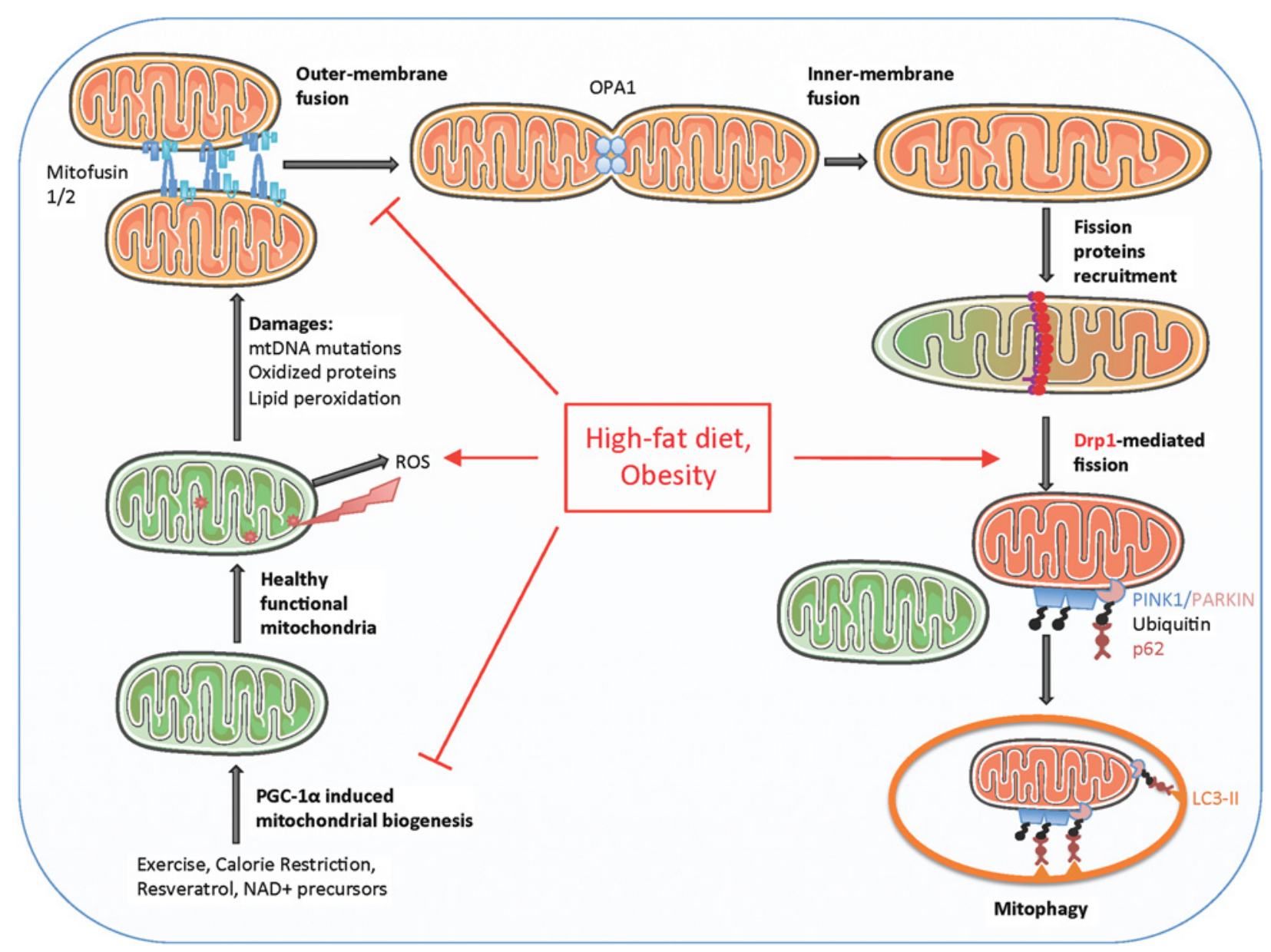

Figure 1 Healthy and impaired mitochondrial dynamics

Following mitochondrial biogenesis, continuous cycles of fusion and fission result in pooling of the mitochondrial contents, allowing mitochondrial adaptation to the environment. Upon damaging of the mitochondria, mitochondrial fusion consists of two steps. First, the outer membranes of two mitochondria fuse, which is mediated by two isoforms of the GTPases Mfn-1/2. Subsequently, the inner membranes fuse, mediated by the dynamin-related protein Opa1. The process of mitochondrial fission requires the activation of Drp-1. Oligomerization and phosphorylation of Drp-1 on the mitochondrial surface causes constriction of the mitochondria and eventual division of the organelle into two fragmented organelles. Drp-1 is recruited to the outer membrane by its receptors. Finally, healthy mitochondria can reintegrate into the mitochondrial network whereas damaged organelles are removed through mitophagy. The selection and degradation process is mediated via ubiquitination of the mitochondria, which is then sensed by p62 and loaded into the autophagosome by LC3-II. Under obesogenic conditions, expression of fusion proteins Mfn-1 and Mfn-2 is reduced, which may lead to a decreased fusion rate between mitochondria. Together with an increased ROS production and an elevated fission protein expression this leads to a fragmentation of the mitochondrial pool hampering mitochondrial function.

Animal models genetically modified for key components of the fission and fusion machinery have been studied for their role in glucose homoeostasis and mitochondrial morphology. Thus, Mfn-2 knockout mice presented fragmented mitochondria, impaired glucose tolerance, high plasma insulin levels and insulin resistance after 14 weeks of high-fat diet, compared with wild type mice [18]. Additionally, at the age of 54 weeks, the Mfn-2 knockout mice showed increased plasma insulin levels during a glucose tolerance test, whereas blood glucose values were similar to the control group [18]. In line with these findings, overexpression of Mfn-2 in rats fed a high-fat diet restored insulin sensitivity and GLUT4 to a level comparable to animals on a chow diet [19]. Thus, rats overexpressing Mfn-2 through adenovirus infection were fed a high-fat diet for 8 weeks and compared with both high- fat and chow fed controls [19]. Similar to the previously described studies, the high-fat diet reduced Mfn-2 protein levels in the control rats. This was accompanied by a reduced glucose infusion rate during a hyperinsulinaemic-euglycaemic clamp, indicating insulin-resistance, as well as reduced total GLUT4 protein and GLUT4 translocation [19]. However, in another study, overexpression of Mfn-2 by transient muscle electroporation in healthy, non-obese, chow-fed rats did not change the rate of mitochondrial oxygen consumption and did not improve the production rate of hydrogen peroxide [20]. Recently, mice with liver-specific knockout of Drp-1 (Drp1LiKO) were shown to be protected against high-fat diet induced obesity compared with the wild type controls. Hepatic mitochondria were less abundant and displayed a swollen phenotype in the Drp1LiKO mice. However, blood 
glucose, triacylglycerol and cholesterol were lowered in Drp1LiKO mice associated with a net improvement in glucose tolerance and insulin signalling assessed by intraperitoneal glucose tolerance test [21].

In line with the findings in cell and animal models, normoglycaemic obese human subjects also displayed reduced protein levels of Mfn-2 in skeletal muscle, which were shown to be negatively correlated with BMI [22]. Furthermore, following a 12-week aerobic training intervention, a decrease in the phosphorylated (active) form of Drp-1 and an increase in Opa1 levels were reported in skeletal muscle from obese subjects with type 2 diabetes [23]. In addition, both whole-body fat oxidation, assessed by indirect calorimetry, and insulin sensitivity negatively correlated with the change of Drp-1 phosphorylation [23].

In conclusion, mitochondrial fusion and fission are tightly controlled in order to keep a healthy pool of mitochondria in the skeletal muscle cells. Several studies have consistently reported that under obesogenic conditions, proteins associated with fusion were down-regulated whereas fission-associated proteins were elevated. These changes are generally accompanied by more fragmented, less effective, ROS-producing mitochondria that may contribute to reduced insulin-sensitivity in skeletal muscle (Figure 1). Indeed, interventions such a physical activity and polyunsaturated fatty acid-enriched diets, clearly associated with metabolic improvements, also restore the protein levels associated with mitochondrial fusion and fission, indicating an improved control of mitochondrial dynamics.

\section{MITOCHONDRIAL PROTEIN QUALITY CONTROL AND STRESS RESPONSE IN OBESITY}

The unfolded protein response (UPR) is a protein quality control mechanism, which has been characterized in several subcellular compartments such as the cytosol, the endoplasmatic reticulum but also in mitochondria. The role of the mitochondrial unfolded protein response (mtUPR) is to maintain the mitochondrial proteome via the production, folding and degradation of proteins and/or to resolve proteotoxic stress such as protein aggregation. Of all mitochondrial proteins, approximately 1500 are transcribed in the nucleus, whereas only 13 are actually derived from the mtDNA. This implies that the vast majority of proteins has to be translocated from the nucleus to the mitochondria [24], for which precise coordination and communication with the nucleus is necessary. To ensure successful shuttling, mitochondrial proteins are labelled with an N-terminal matrix-sequence (MTS), which is recognized by the mitochondrial protein import machinery. Subsequently, the MTS is cleaved off and the newly imported proteins undergo chaperone-assisted folding facilitated by mitochondrial heat shock protein 70 (mtHSP70) immediately upon entering the mitochondrial intermembrane space (IMS) and by the HSP60-HSP10 machinery when these proteins reach the mitochondrial matrix (Figure 2) [25]. Proteotoxic stress, i.e. harmful protein aggregates formed by damaged and/or misfolded proteins, occurs either when the protein import exceeds the capacity of the chaperones to correctly fold them, or through pro- tein damage caused by stressors such as heat or ROS. To resolve this proteotoxic stress, mitochondrial proteases such as the Lon protease (LonP) and the ATP-dependent caseinolytic mitochondrial matrix protease complex (ClpXP) are activated. Whereas LonP recognizes misfolded proteins in general, the ClpXP protease complex recognizes specific recognition motifs, unfolds the misfolded protein and mediates subsequent proteolysis [26]. Although the mechanisms are not fully elucidated, the short peptides that result from the mitochondrial proteolysis are exported to the cytoplasm and ultimately regulate the transcription of stress response genes to aid in the restoration of mitochondrial homoeostasis $[9,26,27]$. Misfolded mitochondrial proteins in the cytoplasm that are directed for transport to the IMS, are ubiquinated and degraded by the cytoplasmic $26 \mathrm{~S}$ proteasome before being imported into the mitochondria. Misfolded proteins that still reach the IMS are degraded by the protease HTRA2 [27].

The activation of the mtUPR can be triggered by various conditions such as protein damage, interference with protein quality control, interference with mitochondrial import and architecture, mtDNA depletion, interference with mitochondrial translation, loss of electron transport chain (ETC) subunits, sirtuin activation and mitochondrial biogenesis [9]. Recently, it was shown though, that the mtUPR could also be activated by a so-called mito-nuclear protein imbalance, i.e. an imbalance between the production of mitochondrial proteins encoded by the nuclear and the mitochondrial DNA [24]. The production of nuclear-encoded ETC components without the correct supply of their counterparts encoded by the mtDNA, or vice versa, will result in unassembled ETC components that stay associated with chaperones, activating the mtUPR $[9,24]$. Although these conditions seem detrimental for mitochondrial health, moderate amounts of stress have in fact shown to be beneficial. Thus, the induction of a mito-nuclear protein imbalance, via knockdown of mitochondrial ribosomal proteins (Mrps5), resulted in a reduction in mitochondrial respiration, activation of the mtUPR and an increased lifespan in worms [24]. Using well-characterized BXD mouse strains, a combination of $\mathrm{C} 57 \mathrm{BL} / 6 \mathrm{~J}$ and $\mathrm{DBA} / 2 \mathrm{~J}$ genomes that display different susceptibilities in traits such as aging and metabolic disorders [28], a robust inverse correlation was found between Mrps5 expression and lifespan [24].

When mitochondria are damaged beyond the capabilities of the repair mechanisms they are removed through a process of mitochondrial autophagy (also called mitophagy) to limit damage caused by dysfunctional mitochondria. The removal of dysfunctional mitochondria is important to maintain efficient mitochondrial energy metabolism, to protect cells against the release of proapoptotic proteins, such as bcl-2, and to prevent excessive reactive oxygen species production [29]. During mitophagy, mitochondria are sequestered into double-membrane structures called autophagosomes and perhaps the most essential signalling molecule in the formation of these autophagosomes is the mTOR kinase (reviewed in [31]). The process of mitophagy is further regulated via PTEN-induced putative kinase 1 (PINK1) and parkin. Thus, when mitochondria are healthy and have a normal membrane potential, PINK1 is constitutively imported into the mitochondria for degradation [29]. However, upon loss of 


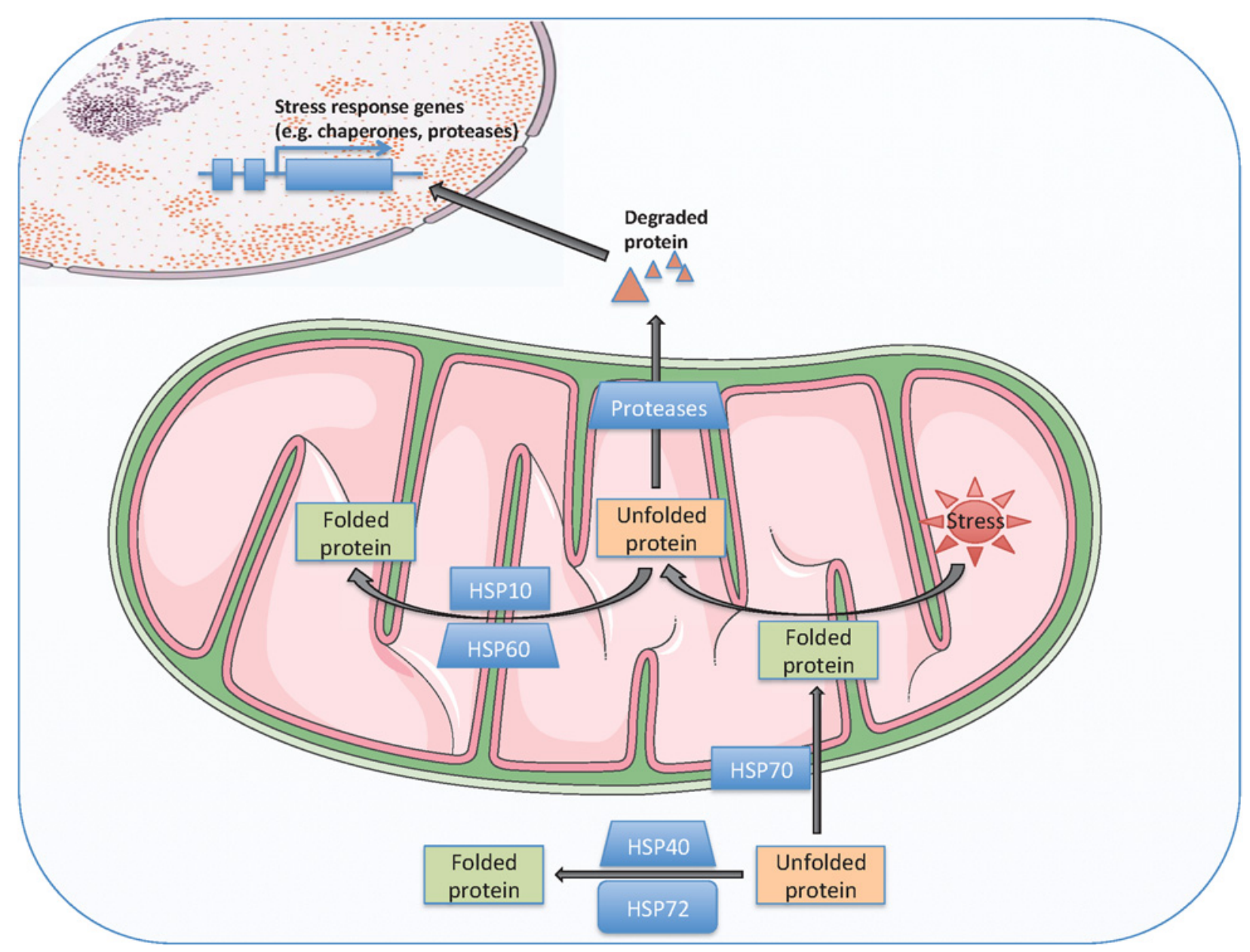

Figure 2 Mitochondrial unfolded protein response in humans

Mitochondrial chaperones and proteases work in concert to repair or abolish misfolded or dysfunctional proteins. In the cytosol, unfolded proteins are assisted by the chaperone HSP72 and its cochaperone HSP4O to acquire their functional structure. Furthermore, on the outer mitochondrial membrane, heat shock protein 70, HSP70, assists in the folding of proteins upon entry into the mitochondria from the cytosol, followed by additional folding by HSP60 and HSP10 in the mitochondrial matrix. When proteotoxic stress occurs, due to stressors such as oxidative stress, carbonylation or heat, proteins can be damaged or unfolded, which in turn leads to the formation of harmful protein aggregates. During proteotoxic stress, damaged or misfolded proteins are taken care of by two distinct pathways. First, the HSP60-HSP10 complex will properly fold the proteins back into their functional structure. If the chaperones system fails to do so, unfolded proteins accumulate in the matrix and proteases are activated. These proteases degrade the unfolded proteins into short peptides that trigger, via a still unclear mechanism, the transcription of stress response genes within the nucleus.

mitochondrial membrane potential, PINK1 is no longer imported into the IMS, and is recruited by Mfn-2 to accumulate at the outer mitochondrial membrane [29]. This initiates the subsequent recruitment and activation of parkin E3 enzyme activity, resulting in the ubiquination of mitochondrial substrates [30]. The elongation of the phagosome membrane and the incorporation of the ubiquinated mitochondria are regulated by the autophagyrelated proteins, the microtubule-associated protein 1A/1B-light chain 3 proteins (LC3) and the multi-functional adaptor molecule p62 [31]. Subsequently, the autophagosomes fuse with lysosomes and the damaged mitochondria are degraded (Figure 1) [31].

Until recently, it was thought that mitochondrial quality control at the protein level (mtUPR) and the organelle level (mitophagy) are separate control mechanisms. Interestingly though, it has been demonstrated that excess loading of unfolded proteins in the mitochondrial matrix is able to initiate PINK1/parkinmediated mitophagy, without the loss of mitochondrial membrane potential [30]. These results suggest an integration of mitochondrial quality control processes at the protein and the organelle level.

\section{Mitochondrial protein quality control in obesity and type 2 diabetes mellitus}

Dysfunction of mitochondrial protein quality control has been associated with obesity. In a mouse model for obesity/diabetes $(d b / d b)$, it has been reported that $42 \%$ of all mitochondrial heat shock protein transcripts showed reduced expression in adipose tissue as compared with lean control mice [32]. This finding was also observed in adipose tissue of high-fat diet-fed mice, 
although to a lesser extent [32]. Furthermore, these results were accompanied by reduced levels of mitochondrial ribosomal proteins and mitochondrial inner and outer membrane translocase proteins in both groups, indicating that both the mtUPR and mitochondrial biogenesis are dysregulated [32].

In addition, genetic ablation of the cytosolic HSP72 (the inducible isoform of HSP70) chaperone in animals has been shown to lead to enlarged, dysmorphic mitochondria, reduced oxidative enzyme activity ( $\beta \mathrm{HAD}$ ), increased intramuscular lipid accumulation and reduced oxidative capacity in skeletal muscle tissue as well as insulin resistance and increased adiposity [33]. In the absence of HSP72, Parkin translocation to depolarized mitochondria was diminished, identifying HSP72 as a crucial mitochondrial stress sensor regulating mitophagy via the ParkinMfn axis [33]. On the other hand, increasing HSP72 by exercise, genetic overexpression or pharmacological stimulation has been shown to result in an increased mitochondrial number and increased oxidative enzyme activity (citrate synthase and $\beta \mathrm{HAD}$ ) [34]. Additionally, targeting HSP72 in skeletal muscle also increased whole-body energy utilization and fatty acid oxidation, preventing lipid accumulation and insulin resistance, independent of changes in proinflammatory signalling [34].

Limited information is available on the status of the mtUPR in skeletal muscle of human obese subjects. However, some evidence for dysfunction of mitochondrial protein quality control has been reported in humans. Thus, protein levels of the cytosolic HSP72 were lower in skeletal muscle of obese and T2DM subjects as compared with lean, healthy age-matched controls, both in the basal state and upon the induction of cellular stress known to activate HSP72 [35,36]. Furthermore, in a relatively large group of overweight type 2 diabetic patients compared with normoglycaemic controls, plasma HSP60 levels were undetectable in $48 \%$ of all subjects. Interestingly, of all subjects with undetectable levels of HSP60 the number of subjects with T2DM was 2-fold higher, suggesting a role for HSP60 in the pathology of T2DM [37].

Furthermore, mitochondrial HSP60 and GRP75 (a HSP70 family member) protein expression were shown to increase significantly in vastus lateralis muscle upon a 2-year lifestyle (diet + exercise) intervention in a large group of middle-aged obese subjects with impaired glucose tolerance, whereas cytosolic heat shock proteins such as HSP72 or HSP90 remained unchanged [38]. Additionally, a positive correlation was observed between the increase in HSP60 and the increase in oxygen radical absorbing capacity (ORAC) values, indicating a possible connection between mitochondrial protein quality control and antioxidant capacity [38].

In another study, the gene and protein expression of the heat shock-related gene DNAJB3 was shown to be down-regulated in both peripheral blood mononuclear cells (PBMCs) and adipose tissue from non-diabetic obese compared with normal-weight control subjects [39]. DNAJB3 is a HSP40 family member and acts as a co-chaperone for HSP70, a major player in the protein quality control network. In addition, a 3-month supervised exercise intervention, known to positively affect mitochondrial metabolism, was able to restore the expression of DNAJB3 in adipose tissue.
Partly in contrast with the previously mentioned studies however, increased HSP60, HSC70, HSP72, HSP90 and GRP94 and decreased DNAJB3 levels (mRNA and protein) were reported in adipose tissue and PBMCs of obese compared with lean control subjects [40]. Again, a 3-month exercise intervention was able to restore the gene expression of most HSPs to levels comparable to lean control subjects in adipose tissue [40].

In conclusion, mitochondrial protein quality control mechanisms play an important role in the maintenance of a healthy mitochondrial population in several metabolic tissues. Although the available data in skeletal muscle are limited and far from conclusive, animal and human studies indicate that important regulators of the mitochondrial protein quality control are altered in obesity and T2DM and can be normalized by physical activity, known to positively affect skeletal muscle mitochondrial metabolism. Additionally, also the cytosolic chaperone HSP72 was linked to obesity-related metabolic disease. This is underscored by the fact that BGP-15, an activator of HSP72, is currently the subject of a multicentre human clinical trial for the treatment of type 2 diabetes [34].

\section{MIRNAS INVOLVED IN THE REGULATION OF MITOCHONDRIAL FUNCTION}

miRNAs are small, single-stranded noncoding RNAs that regulate the production of cellular proteins. miRNAs are initially transcribed from their own genes or from introns, as part of a larger miRNA precursor termed pri-miRNA, which is subsequently processed within the nucleus to form pre-miRNA. This pre-miRNA is then exported to the cytoplasm, bound and cleaved by the endoribonuclease DICER, resulting in a double-strand miRNA duplex. The duplex is then targeted by the RNA-induced silencing complex (RISC), which processes one strand (the passenger strand), resulting in a single-strand, mature miRNA. Bound to the Argonaute 2 protein (AGO2) mature miRNA binds to its target messenger RNA via a complementary base pairing mechanism, binding a small sequence mainly - but not exclusively - located at the $3^{\prime}$ untranslated region (UTR) of the mRNA. Upon binding, miRNAs can regulate gene expression either by inhibiting the translation of the protein or by promoting the degradation of the mRNA. A single miRNA can target over 100 mRNAs, illustrating their wide influence over cellular processes. On the other hand, a single gene can be targeted by up to a thousand miRNAs, adding complexity to the understanding of the regulation of gene expression. The biology behind miRNA regulation of gene expression has been extensively studied and reviewed [41].

\section{miRNAs in obesity and type $\mathbf{2}$ diabetes mellitus}

miRNAs have also been linked to the regulation of skeletal muscle metabolism in the context of obesity and diabetes (Table 1). Thus, miRNA expression profiles were determined in muscle biopsies from obese T2DM patients and compared with an ageand BMI-matched healthy control group [42]. Using miRNA microarrays, 62 miRNAs were found to be differentially expressed between the healthy obese and T2DM populations. 
Table 1 Overview of miRNAs linked to obesity, T2DM and the regulation of muscle mitochondrial function. *Indicates if the paper provided experimental support for the putative underlying mechanism, i.e. which mRNA is targeted by the miRNA of interest.

\begin{tabular}{|c|c|c|c|c|c|c|}
\hline Study & MiRNA & Species & $\begin{array}{l}\text { Tissue/cell } \\
\text { type }\end{array}$ & Target* & Treatment & Main outcomes \\
\hline $\begin{array}{l}\text { Gallagher et al. } \\
\text { [42] }\end{array}$ & MiR-133a & Human & Muscle & & & MiR-133a $\downarrow$ in T2DM vs. healthy control subjects \\
\hline $\begin{array}{l}\text { Bork Jensen } \\
\text { et al. [43] }\end{array}$ & $\begin{array}{l}\text { MiR-15b } \\
\text { MiR-16 } \\
\text { MiR-106b }\end{array}$ & Human & Muscle & & & $\begin{array}{l}\text { MiRNAs } \downarrow \text { in T2DM vs. healthy twin pairs, } \\
\text { MiRNAs negatively correlated with high HbA1c } \\
\text { MiR-15/16 involved in the insulin signaling pathway }\end{array}$ \\
\hline \multirow{3}{*}{$\begin{array}{l}\text { Agarwal et al. } \\
\text { [44] }\end{array}$} & \multirow[t]{3}{*}{ MiR-135a } & Human & Muscle & IRS2 & & MiR-135a 1.5-fold $\uparrow$ in T2DM \\
\hline & & Mouse & Muscle & & & MiR-135a 2.5-fold $\uparrow$ in T2DM db/db mice \\
\hline & & Mouse & Muscle & & Anti-miR-135a & Blood glucose $\downarrow$ and glucose tolerance $\uparrow$ \\
\hline Gao et al. [45] & Let-7 & Human & Muscle & $\begin{array}{l}\text { Insulin } \\
\text { receptor }\end{array}$ & & $\begin{array}{l}\text { Let-7 } \uparrow \text { in T2DM, insulin signaling } \downarrow \text { and glucose } \\
\text { uptake } \downarrow\end{array}$ \\
\hline Cui et al. [48] & MiR-140 & Rat & Heart & & MiR-140 overexpression & Mfn-1 $\downarrow$, fragmented mitochondria \\
\hline $\begin{array}{l}\text { El Azzouzi et al. } \\
\text { [49] }\end{array}$ & $\begin{array}{l}\text { MiR-199a- } \\
214\end{array}$ & Mouse & Heart & PPARס & $\begin{array}{l}\text { Anti-miR-199a and miR- } \\
214\end{array}$ & $\begin{array}{l}\text { PPAR } \delta \uparrow, \text { mitochondrial fatty acid oxidation } \uparrow \text { and } \\
\text { cardiac function } \uparrow\end{array}$ \\
\hline $\begin{array}{l}\text { Yamamoto et al. } \\
{[50]}\end{array}$ & MiR-494 & Mouse & $\mathrm{C} 2 \mathrm{C} 12$ & $\begin{array}{l}\text { mtTFA } \\
\text { FOXJ3 }\end{array}$ & Anti-miR-494 & Mitochondrial content $\uparrow$ \\
\hline \multirow[t]{2}{*}{ Aoi et al. [51] } & \multirow[t]{2}{*}{ MiR-696 } & \multirow[t]{2}{*}{ Mouse } & \multirow[t]{2}{*}{ Muscle } & \multirow[t]{2}{*}{ PGC1 $\alpha$} & Physical activity & $\begin{array}{l}\text { MiR-696 } \downarrow \text {, fat oxidation } \uparrow \text { and mitochondrial } \\
\text { biogenesis } \uparrow\end{array}$ \\
\hline & & & & & Immobilization & MiR-696 ^ \\
\hline \multirow[t]{3}{*}{ Zhang et al. [53] } & \multirow[t]{3}{*}{ MiR-106b } & \multirow[t]{3}{*}{ Mouse } & \multirow[t]{3}{*}{$\mathrm{C} 2 \mathrm{C} 12$} & & $\begin{array}{l}\text { MiR-106b } \\
\text { overexpression }\end{array}$ & $\begin{array}{l}\text { Insulin-stimulated glucose uptake } \downarrow \text { and GLUT-4 } \\
\text { translocation } \downarrow\end{array}$ \\
\hline & & & & & $\begin{array}{l}\text { TNF } \alpha \text { induced insulin } \\
\text { resistance }\end{array}$ & MiR-106b $\uparrow$ \\
\hline & & & & & TNFa + anti-miR-106b & $\begin{array}{l}\text { Insulin stimulated glucose uptake } \uparrow \text {, partially } \\
\text { restored mitochondrial morphology, mfn2 } \uparrow \text {, ATP } \\
\text { synthesis } \uparrow \text { and ROS production } \downarrow \text {, compared to } \\
\text { just TNFa. }\end{array}$ \\
\hline \multirow[t]{2}{*}{$\begin{array}{l}\text { Mohamed et al. } \\
\text { [54] }\end{array}$} & \multirow[t]{2}{*}{ MiR-149 } & Mouse & $\mathrm{C} 2 \mathrm{C} 12$ & & MiR-149 overexpression & $\begin{array}{l}\text { NAD+ and SIRT1 protein } \uparrow \text { via targeting of PARP-2, } \\
\text { PGC } 1 \alpha \text { deacetylation } \uparrow, \text { mitochondrial density } \uparrow\end{array}$ \\
\hline & & Mouse & Muscle & PARP-2 & High fat diet & MiR-149 $\downarrow$, associated with PARP-2 $\uparrow$ \\
\hline
\end{tabular}

More specifically, the muscle-specific miRNA miR-133a was down-regulated in type 2 diabetic subjects and miR-133a expression displayed a tight relationship with fasting glucose level [42]. Furthermore, a recent study, revealed differential expression of miRNAs between monozygotic twins with T2DM and their non-diabetic co-twins [43], although it should be noted that $80 \%$ of the non-diabetic co-twins were already characterized by impaired glucose tolerance [43]. Nonetheless, 20 miRNAs, including miR-15b, miR-16 and miR-106b, of the 571 studied were down-regulated, whereas no miRNAs were up-regulated in this cohort [43]. Interestingly, a strong negative correlation between miR-15b expression and $\mathrm{HbA1c}$ was observed and subsequent pathway analysis of changes in miRNAs expression revealed that the miR-15/16 family may regulate the insulin-signalling pathway [43]. This relation was subsequently confirmed in vitro, using both L6 rat myoblasts and human primary skeletal muscle cells. However, the mechanisms behind the regulation of the insulinsignalling pathway remain unclear.

Nevertheless, several other studies also linked the regulation of glucose metabolism in skeletal muscle to specific miRNAs. Thus, after a microarray screening, miR-135a has been identified to target the insulin receptor substrate 2 (IRS2) in the insulinsignalling pathway thereby regulating glucose uptake [44]. Furthermore, in skeletal muscle, miR-135a expression level was increased 2.5-fold and 1.5-fold in diabetic mice and humans, respectively, compared with healthy controls and treating mice with anti-miR-135a for 3 days restored blood glucose levels and glucose tolerance. Finally, the long non-coding RNA (lncRNA) H19 was shown to be decreased in skeletal muscle of type 2 diabetic humans and animals, leading to higher bioavailability of the miRNA let-7, impairing the mRNA coding for the insulin receptor, a let-7 target. This finding was linked to diminished insulin signalling and decreased glucose uptake [45].

\section{miRNAs in the regulation of mitochondrial metabolism}

Recent studies have shown the involvement of miRNAs in the regulation of mitochondrial metabolism (Table 1). Thus, using deep sequencing techniques on total RNAs extracted from mitochondria isolated from human HEK293 and HeLa cell lines, Sripada et al. [46] demonstrated that $2-5 \%$ of the sequences were miRNAs. Interestingly, the authors showed co-localization of miRNA and Argonaute proteins within the mitochondria supporting the presence of active silencing complexes within the organelle. Also, in isolated mitochondria from human skeletal muscle cells, the presence of at least 50 different miRNAs and pre-miRNAs has been demonstrated [47].

Furthermore, besides being present in mitochondria, miRNAs have also been shown to regulate several aspects of mitochondrial function. In cardiac tissue, overexpression of miR140 in rat cardiomyocytes negatively regulated the mRNA coding for Mfn-1, which translated into more fragmented mitochondria [48]. This finding clearly illustrates that miRNAs are capable of regulating mitochondrial dynamics. Furthermore, silencing the miR family 199-214 in vivo increased the protein level of its molecular target $\operatorname{PPAR} \delta$, restored cardiac mitochondrial fatty acid oxidation and improved cardiac function in transverse aortic constriction (TAC)-induced heart failure in mice [49]. 
Besides cardiac tissue, miRNAs have also been implicated in skeletal muscle mitochondrial metabolism. Thus, in $\mathrm{C} 2 \mathrm{C} 12$ muscle cells, miR-494 was identified as an activator of mitochondrial biogenesis via the regulation of mitochondrial transcription factor A (mtTFA) and Forkhead Box J3 (FOXJ3), both involved in mitochondrial biogenesis and muscle growth [50]. Furthermore, the expression of miR-696, which targets the mitochondrial biogenesis factor PGC-1 $\alpha$, was reduced in skeletal muscle upon physical activity whereas immobilization of mice increased the expression of miR-696 [51]. The changes in the expression of miR-696 were paralleled by changes in mitochondrial biogenesis and fatty acid oxidation [51].

Given the clear association between skeletal muscle mitochondrial capacity and insulin sensitivity [52], the interrelation between miRNAs, muscle mitochondria and insulin sensitivity is of great interest. However, the available research data on this topic are scarce, although some reports exist. Thus, in $\mathrm{C} 2 \mathrm{C} 12$ muscle cells, Zhang et al. [53], showed that the overexpression of miR-106b reduced insulin-stimulated glucose uptake and GLUT4 translocation. Furthermore, miR-106b was induced in $\mathrm{TNF}-\alpha$ induced insulin-resistant $\mathrm{C} 2 \mathrm{C} 12$ and silencing of miR$106 \mathrm{~b}$ restored insulin-stimulated glucose uptake upon TNF- $\alpha$ treatment, which was associated with an improved GLUT4 translocation [53]. Interestingly, TNF- $\alpha$ challenged, insulin-resistant cells presented smaller and denser mitochondria while silencing miR-106b partially restored these aberrations in mitochondrial ultra-structure, paralleled by an increase in Mfn- 2 protein levels, a partly restored ATP synthesis rate and a decreased ROS production [53].

Furthermore, Mohamed et al. demonstrated that miR-149 via its main target poly(ADP-ribosyl) transferase-like 2 protein (PARP-2) - was able to manipulate the levels of NAD+ and SIRT-1 [54]. Indeed, C2C12 myotubes overexpressing miR-149 showed increased NAD + and SIRT-1 proteins levels, which translated into a higher PGC- $1 \alpha$ deacetylation, increased mitochondrial density and increased translation and transduction of genes involved in oxidative capacity (COX1, COX2, Cytc, SDH) [54]. In line with this, insulin-resistant skeletal muscle from high-fat fed mice displayed lower levels of miR-149 associated with increased PARP-2 protein levels.

Taken together, several studies support a strong involvement of miRNAs in the regulation of mitochondrial metabolism and insulin sensitivity - also in skeletal muscle - and targeting these miRNAs may in turn affect metabolic health, in the context of obesity.

\section{CONCLUSION}

In this review, we have discussed several novel aspects of skeletal muscle mitochondrial metabolism in relation to obesity and associated metabolic disease. Under obesogenic conditions, the mitochondrial dynamics alter in favour of mitochondrial fission resulting in smaller, fragmented mitochondria with impaired function. In addition, also mitochondrial protein quality control appears to be altered in both obese and T2DM subjects. Inter- ventions such a physical activity and specific diets - known to augment skeletal muscle mitochondrial metabolism as well as metabolic health - also positively impact markers of mitochondrial dynamics and mtUPR activity in skeletal muscle. Finally, miRNAs bring another dimension to the regulation of skeletal muscle metabolism and miRNA expression profiles are changed upon obesity and T2DM. Furthermore, there are indications that (silencing) specific miRNAs can positively affect mitochondrial metabolism, also in skeletal muscle. Given the positive relationship between skeletal muscle mitochondrial oxidative capacity and metabolic health, it could be postulated that targeting these particular miRNAs may also improve glucose homeostasis.

Although this research field is rapidly developing, the available information on these novel aspects of skeletal muscle mitochondrial metabolism is still fairly limited and experiments that establish cause and effect relations, determine the human relevance and reveal the therapeutic potential of targeting these pathways are eagerly awaited.

\section{FUNDING}

This work was supported by the Netherlands Organization for Scientific Research (NWO) [grant numbers 918.96 .618 (to P.S.) and 917.14.358 (to J.H.)]; and the Dutch Diabetes Research Foundation [grant number 2013.82.1639 (to J.H.)].

\section{REFERENCES}

1 Ng, M., Fleming, T., Robinson, M., Thomson, B., Graetz, N., Margono, C., Mullany, E.C., Biryukov, S., Abbafati, C., Abera, S.F. et al. (2014) Global, regional, and national prevalence of overweight and obesity in children and adults during 1980-2013: a systematic analysis for the Global Burden of Disease Study 2013. Lancet 384, 766-781 CrossRef PubMed

2 Goodpaster, B.H., Theriault, R., Watkins, S.C. and Kelley, D.E. (2000) Intramuscular lipid content is increased in obesity and decreased by weight loss. Metabolism 49, 467-472 CrossRef PubMed

3 DeFronzo, R.A. and Tripathy, D. (2009) Skeletal muscle insulin resistance is the primary defect in type 2 diabetes. Diabetes Care 32 Suppl 2, S157-S163 CrossRef PubMed

4 Coen, P.M., Hames, K.C., Leachman, E.M., DeLany, J.P., Ritov, V.B., Menshikova, E.V., Dube, J.J., Stefanovic-Racic, M., Toledo, F.G. and Goodpaster, B.H. (2013) Reduced skeletal muscle oxidative capacity and elevated ceramide but not diacylglycerol content in severe obesity. Obesity (Silver Spring) 21, 2362-2371 CrossRef PubMed

5 Kelley, D.E., He, J., Menshikova, E.V. and Ritov, V.B. (2002) Dysfunction of mitochondria in human skeletal muscle in type 2 diabetes. Diabetes 51, 2944-2950 CrossRef PubMed

6 Kim, J.Y., Hickner, R.C., Cortright, R.L., Dohm, G.L. and Houmard, J.A. (2000) Lipid oxidation is reduced in obese human skeletal muscle. Am. J. Physiol. Endocrinol. Metab. 279, E1039-E1044 PubMed

7 Lefort, N., Glancy, B., Bowen, B., Willis, W.T., Bailowitz, Z., De Filippis, E.A., Brophy, C., Meyer, C., Hojlund, K., Yi, Z. and Mandarino, L.J. (2010) Increased reactive oxygen species production and lower abundance of complex I subunits and carnitine palmitoyltransferase $1 \mathrm{~B}$ protein despite normal mitochondrial respiration in insulin-resistant human skeletal muscle. Diabetes 59, 2444-2452 $\underline{\text { CrossRef PubMed }}$ 
8 Smirnova, E., Shurland, D.L., Ryazantsev, S.N. and van der Bliek, A.M. (1998) A human dynamin-related protein controls the distribution of mitochondria. J. Cell Biol. 143, 351-358 CrossRef PubMed

9 Jovaisaite, V. and Auwerx, J. (2015) The mitochondrial unfolded protein response-synchronizing genomes. Curr. Opin. Cell Biol. 33, 74-81 CrossRef PubMed

10 Roy, M., Reddy, PH., lijima, M. and Sesaki, H. (2015) Mitochondrial division and fusion in metabolism. Curr. Opin. Cell Biol. 33, 111-118 CrossRef PubMed

11 Iqbal, S. and Hood, D.A. (2015) The role of mitochondrial fusion and fission in skeletal muscle function and dysfunction. Front. Biosci. (Landmark Ed) 20, 157-172 CrossRef PubMed

12 Loson, O.C., Song, Z., Chen, H. and Chan, D.C. (2013) Fis1, Mff, MiD49, and MiD51 mediate Drp1 recruitment in mitochondrial fission. Mol. Biol. Cell 24, 659-667 CrossRef PubMed

13 Kobayashi, S. and Liang, Q. (2015) Autophagy and mitophagy in diabetic cardiomyopathy. Biochim. Biophys. Acta 1852, 252-261 CrossRef PubMed

14 Jheng, H.F., Tsai, P.J., Guo, S.M., Kuo, L.H., Chang, C.S., Su, I.J., Chang, C.R. and Tsai, Y.S. (2012) Mitochondrial fission contributes to mitochondrial dysfunction and insulin resistance in skeletal muscle. Mol. Cell. Biol. 32, 309-19 CrossRef PubMed

15 Nie, Q., Wang, C., Song, G., Ma, H., Kong, D., Zhang, X., Gan, K. and Tang, Y. (2014) Mitofusin 2 deficiency leads to oxidative stress that contributes to insulin resistance in rat skeletal muscle cells. Mol. Biol. Rep. 41, 6975-6983 CrossRef PubMed

16 Liu, R., Jin, P., Yu, L., Wang, Y., Han, L., Shi, T. and Li, X. (2014) Impaired mitochondrial dynamics and bioenergetics in diabetic skeletal muscle. PLoS One 9, e92810 CrossRef PubMed

17 Lionetti, L., Mollica, M.P., Donizzetti, I., Gifuni, G., Sica, R., Pignalosa, A., Cavaliere, G., Gaita, M., De Filippo, C., Zorzano, A. and Putti, R. (2014) High-lard and high-fish-oil diets differ in their effects on function and dynamic behaviour of rat hepatic mitochondria. PLoS One 9, e92753 CrossRef PubMed

18 Sebastian, D., Hernandez-Alvarez, M.I., Segales, J., Sorianello, E., Munoz, J.P., Sala, D., Waget, A., Liesa, M., Paz, J.C., Gopalacharyulu, P. et al. (2012) Mitofusin 2 (Mfn2) links mitochondrial and endoplasmic reticulum function with insulin signaling and is essential for normal glucose homeostasis. Proc. Natl. Acad. Sci. U.S.A. 109, 5523-5528 CrossRef PubMed

19 Kong, D., Song, G., Wang, C., Ma, H., Ren, L., Nie, Q., Zhang, X. and Gan, K. (2013) Overexpression of mitofusin 2 improves translocation of glucose transporter 4 in skeletal muscle of highfat dietfed rats through AMPactivated protein kinase signaling. Mol. Med. Rep. 8, 205-210 PubMed

20 Lally, J.S., Herbst, E.A., Matravadia, S., Maher, A.C., Perry, C.G., Ventura-Clapier, R. and Holloway, G.P. (2013) Over-expressing mitofusin-2 in healthy mature mammalian skeletal muscle does not alter mitochondrial bioenergetics. PLoS One 8, e55660 CrossRef PubMed

21 Wang, L., Ishihara, T., Ibayashi, Y., Tatsushima, K., Setoyama, D., Hanada, Y., Takeichi, Y., Sakamoto, S., Yokota, S., Mihara, K. et al. (2015) Disruption of mitochondrial fission in the liver protects mice from diet-induced obesity and metabolic deterioration. Diabetologia 58, 2371-2380 CrossRef PubMed

22 Bach, D., Pich, S., Soriano, F.X., Vega, N., Baumgartner, B., Oriola, J., Daugaard, J.R., Lloberas, J., Camps, M., Zierath, J.R. et al. (2003) Mitofusin-2 determines mitochondrial network architecture and mitochondrial metabolism. A novel regulatory mechanism altered in obesity. J. Biol. Chem. 278, 17190-17197 CrossRef PubMed

23 Fealy, C.E., Mulya, A., Lai, N. and Kirwan, J.P. (2014) Exercise training decreases activation of the mitochondrial fission protein dynamin-related protein-1 in insulin-resistant human skeletal muscle. J. Appl. Physiol. (1985) 117, 239-245

CrossRef PubMed
24 Houtkooper, R.H., Mouchiroud, L., Ryu, D., Moullan, N., Katsyuba, E., Knott, G., Williams, R.W. and Auwerx, J. (2013) Mitonuclear protein imbalance as a conserved longevity mechanism. Nature 497, 451-457 CrossRef PubMed

25 Chacinska, A., Koehler, C.M., Milenkovic, D., Lithgow, T. and Pfanner, N. (2009) Importing mitochondrial proteins: machineries and mechanisms. Cell 138, 628-644 CrossRef PubMed

26 Al-Furoukh, N., lanni, A., Nolte, H., Holper, S., Kruger, M., Wanrooij, S. and Braun, T. (2015) ClpX stimulates the mitochondrial unfolded protein response (UPR) in mammalian cells. Biochim. Biophys. Acta 1853, 2580-2591

27 Jovaisaite, V., Mouchiroud, L. and Auwerx, J. (2014) The mitochondrial unfolded protein response, a conserved stress response pathway with implications in health and disease. J. Exp. Biol. 217 (Pt 1), 137-143 CrossRef PubMed

28 Andreux, P.A., Williams, E.G., Koutnikova, H., Houtkooper, R.H., Champy, M.F., Henry, H., Schoonjans, K., Williams, R.W. and Auwerx, J. (2012) Systems genetics of metabolism: the use of the BXD murine reference panel for multiscalar integration of traits. Cell 150, 1287-1299 CrossRef PubMed

29 Disatnik, M.H., Hwang, S., Ferreira, J.C. and Mochly-Rosen, D. (2015) New therapeutics to modulate mitochondrial dynamics and mitophagy in cardiac diseases. J. Mol. Med. (Berl) 93, 279-287 CrossRef PubMed

30 Jin, S.M. and Youle, R.J. (2013) The accumulation of misfolded proteins in the mitochondrial matrix is sensed by PINK1 to induce PARK2/Parkin-mediated mitophagy of polarized mitochondria. Autophagy 9, 1750-1757 CrossRef PubMed

31 Glick, D., Barth, S. and Macleod, K.F. (2010) Autophagy: cellular and molecular mechanisms. J. Pathol. 221, 3-12 CrossRef PubMed

32 Rong, J.X., Qiu, Y., Hansen, M.K., Zhu, L., Zhang, V., Xie, M., Okamoto, Y., Mattie, M.D., Higashiyama, H., Asano, S. et al. (2007) Adipose mitochondrial biogenesis is suppressed in $\mathrm{db} / \mathrm{db}$ and high-fat diet-fed mice and improved by rosiglitazone. Diabetes 56, 1751-1760 CrossRef PubMed

33 Drew, B.G., Ribas, V., Le, J.A., Henstridge, D.C., Phun, J., Zhou, Z., Soleymani, T., Daraei, P., Sitz, D., Vergnes, L. et al. (2014) HSP72 is a mitochondrial stress sensor critical for Parkin action, oxidative metabolism, and insulin sensitivity in skeletal muscle. Diabetes 63, 1488-1505 CrossRef PubMed

34 Henstridge, D.C., Bruce, C.R., Drew, B.G., Tory, K., Kolonics, A., Estevez, E., Chung, J., Watson, N., Gardner, T., Lee-Young, R.S. et al. (2014) Activating HSP72 in rodent skeletal muscle increases mitochondrial number and oxidative capacity and decreases insulin resistance. Diabetes 63, 1881-1894 CrossRef PubMed

35 Bruce, C.R., Carey, A.L., Hawley, J.A. and Febbraio, M.A. (2003) Intramuscular heat shock protein 72 and heme oxygenase-1 mRNA are reduced in patients with type 2 diabetes: evidence that insulin resistance is associated with a disturbed antioxidant defense mechanism. Diabetes 52, 2338-2345

CrossRef PubMed

36 Chung, J., Nguyen, A.K., Henstridge, D.C., Holmes, A.G., Chan, M.H., Mesa, J.L., Lancaster, G.I., Southgate, R.J., Bruce, C.R., Duffy, S.J. et al. (2008) HSP72 protects against obesity-induced insulin resistance. Proc. Natl. Acad. Sci. U.S.A. 105, 1739-1744 CrossRef PubMed

37 Imatoh, T., Sugie, T., Miyazaki, M., Tanihara, S., Baba, M., Momose, Y., Uryu, Y. and Une, H. (2009) Is heat shock protein 60 associated with type 2 diabetes mellitus? Diabetes Res. Clin. Pract. 85, 208-212 CrossRef PubMed

38 Venojarvi, M., Aunola, S., Puhke, R., Marniemi, J., Hamalainen, H., Halonen, J.P., Lindstrom, J., Rastas, M., Hallsten, K., Nuutila, P. et al. (2008) Exercise training with dietary counselling increases mitochondrial chaperone expression in middle-aged subjects with impaired glucose tolerance. BMC Endocr. Disord. 8, 3 CrossRef PubMed 
39 Abubaker, J., Tiss, A., Abu-Farha, M., Al-Ghimlas, F., Al-Khairi, I., Baturcam, E., Cherian, P., Elkum, N., Hammad, M., John, J. et al. (2013) DNAJB3/HSP-40 cochaperone is downregulated in obese humans and is restored by physical exercise. PLoS One $\mathbf{8}$, e69217 CrossRef PubMed

40 Tiss, A., Khadir, A., Abubaker, J., Abu-Farha, M., Al-Khairi, I., Cherian, P., John, J., Kavalakatt, S., Warsame, S., Al-Ghimlas, F. et al. (2014) Immunohistochemical profiling of the heat shock response in obese non-diabetic subjects revealed impaired expression of heat shock proteins in the adipose tissue. Lipids Health Dis. 13, 106 CrossRef PubMed

41 Bartel, D.P. (2004) MicroRNAs: genomics, biogenesis, mechanism, and function. Cell 116, 281-297 CrossRef PubMed

42 Gallagher, I.J., Scheele, C., Keller, P., Nielsen, A.R., Remenyi, J., Fischer, C.P., Roder, K., Babraj, J., Wahlestedt, C., Hutvagner, G. et al. (2010) Integration of microRNA changes in vivo identifies novel molecular features of muscle insulin resistance in type 2 diabetes. Genome. Med. 2, 9 CrossRef PubMed

43 Bork-Jensen, J., Scheele, C., Christophersen, D.V., Nilsson, E., Friedrichsen, M., Fernandez-Twinn, D.S., Grunnet, L.G., Litman, T., Holmstrom, K. et al. (2015) Glucose tolerance is associated with differential expression of microRNAs in skeletal muscle: results from studies of twins with and without type 2 diabetes. Diabetologia 58, 363-373 CrossRef PubMed

44 Agarwal, P., Srivastava, R., Srivastava, A.K., Ali, S. and Datta, M. (2013) miR-135a targets IRS2 and regulates insulin signaling and glucose uptake in the diabetic gastrocnemius skeletal muscle. Biochim. Biophys. Acta 1832, 1294-1303 CrossRef PubMed

45 Gao, Y., Wu, F., Zhou, J., Yan, L., Jurczak, M.J., Lee, H.Y., Yang, L., Mueller, M., Zhou, X.B., Dandolo, L. et al. (2014) The H19/let-7 double-negative feedback loop contributes to glucose metabolism in muscle cells. Nucleic Acids Res. 42, 13799-13811 CrossRef PubMed

46 Sripada, L., Tomar, D., Prajapati, P., Singh, R., Singh, A.K. and Singh, R. (2012) Systematic analysis of small RNAs associated with human mitochondria by deep sequencing: detailed analysis of mitochondrial associated miRNA. PLoS One 7, e44873 $\underline{\text { CrossRef PubMed }}$
47 Barrey, E., Saint-Auret, G., Bonnamy, B., Damas, D., Boyer, O. and Gidrol, X. (2011) Pre-microRNA and mature microRNA in human mitochondria. PloS one 6, e20220 CrossRef PubMed

48 Li, J., Li, Y., Jiao, J., Wang, J., Li, Y., Qin, D. and Li, P. (2014) Mitofusin 1 is negatively regulated by microRNA 140 in cardiomyocyte apoptosis. Mol. Cell Biol. 34, 1788-1799 CrossRef PubMed

49 el Azzouzi, H., Leptidis, S., Dirkx, E., Hoeks, J., van Bree, B., Brand, K., McClellan, E.A., Poels, E., Sluimer, J.C., van den Hoogenhof, M.M. et al. (2013) The hypoxia-inducible microRNA cluster miR-199a approximately 214 targets myocardial PPARdelta and impairs mitochondrial fatty acid oxidation. Cell Metab. 18, 341-354 CrossRef PubMed

50 Yamamoto, H., Morino, K., Nishio, Y., Ugi, S., Yoshizaki, T., Kashiwagi, A. and Maegawa, H. (2012) MicroRNA-494 regulates mitochondrial biogenesis in skeletal muscle through mitochondrial transcription factor A and Forkhead box j3. Am. J. Physiol. Endocrinol. Metab. 303, E1419-E1427 CrossRef PubMed

51 Aoi, W., Naito, Y., Mizushima, K., Takanami, Y., Kawai, Y., Ichikawa, H. and Yoshikawa, T. (2010) The microRNA miR-696 regulates $P G C-1\{$ alpha\} in mouse skeletal muscle in response to physical activity. Am. J. Physiol. Endocrinol. Metab. 298, E799-E806 CrossRef PubMed

52 Hoeks, J. and Schrauwen, P. (2012) Muscle mitochondria and insulin resistance: a human perspective. Trends Endocrinol. Metab. 23, 444-450 CrossRef PubMed

53 Zhang, Y., Yang, L., Gao, Y.F., Fan, Z.M., Cai, X.Y., Liu, M.Y., Guo, X.R., Gao, C.L. and Xia, Z.K. (2013) MicroRNA-106b induces mitochondrial dysfunction and insulin resistance in $\mathrm{C} 2 \mathrm{C} 12$ myotubes by targeting mitofusin-2. Mol. Cell. Endocrinol. 381 230-240 CrossRef PubMed

54 Mohamed, J.S., Hajira, A., Pardo, P.S. and Boriek, A.M. (2014) MicroRNA-149 inhibits PARP-2 and promotes mitochondrial biogenesis via SIRT-1/PGC-1alpha network in skeletal muscle. Diabetes 63, 1546-1559 $\underline{\text { CrossRef PubMed }}$ 